\title{
Development of a general calibration model and long-term performance evaluation of low-cost sensors for air pollutant gas monitoring
}

\section{Carl Malings et al.}

Correspondence to: Carl Malings (cmalings@andrew.cmu.edu) 


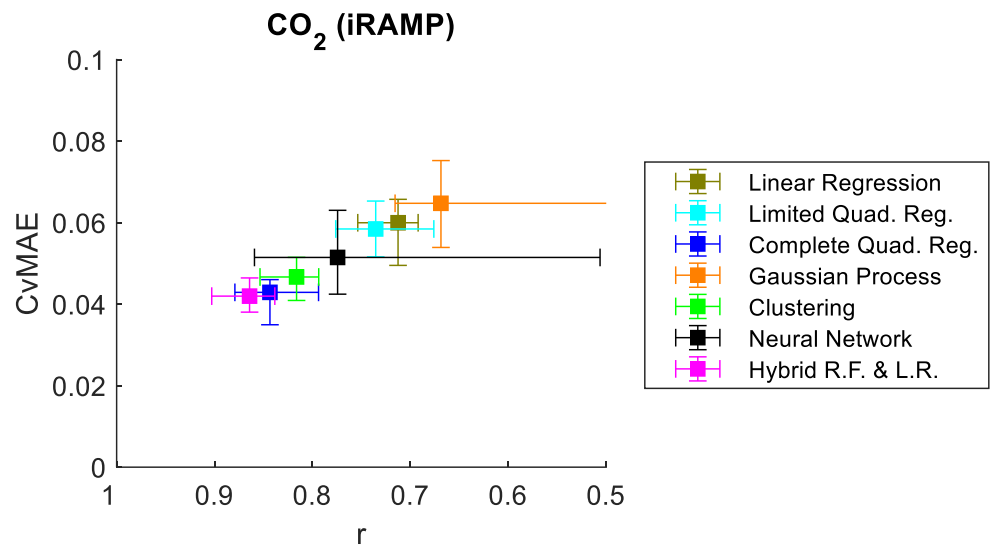

Figure S1. Results corresponding to Fig. 2 for $\mathrm{CO}_{2}$.

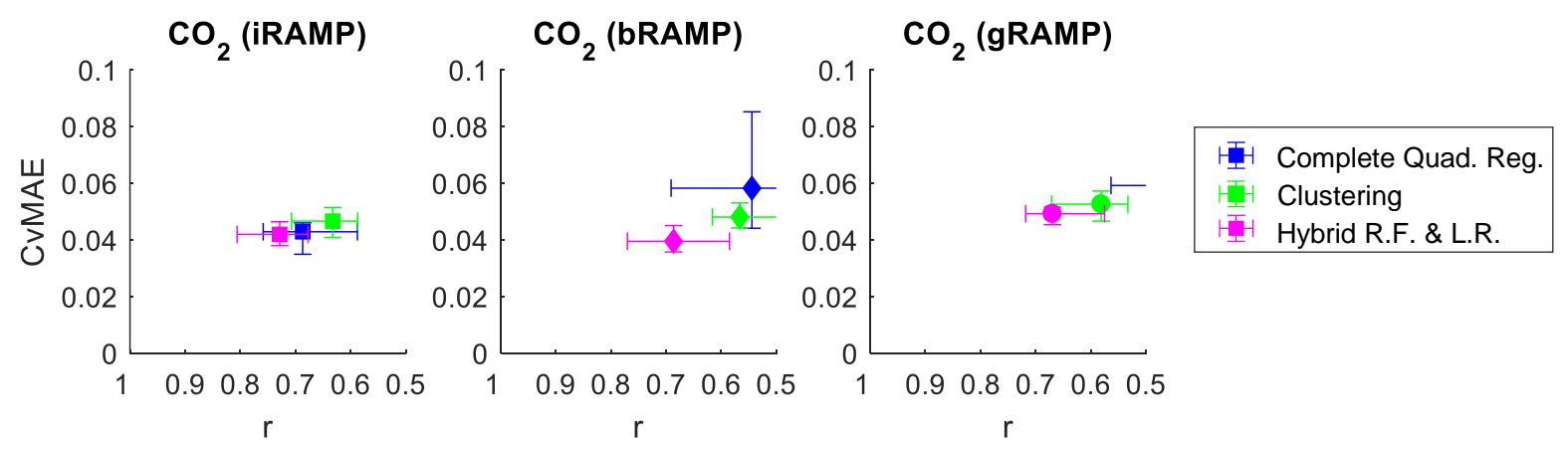

Figure S2. Results corresponding to Fig. 3 for $\mathrm{CO}_{2}$.

5
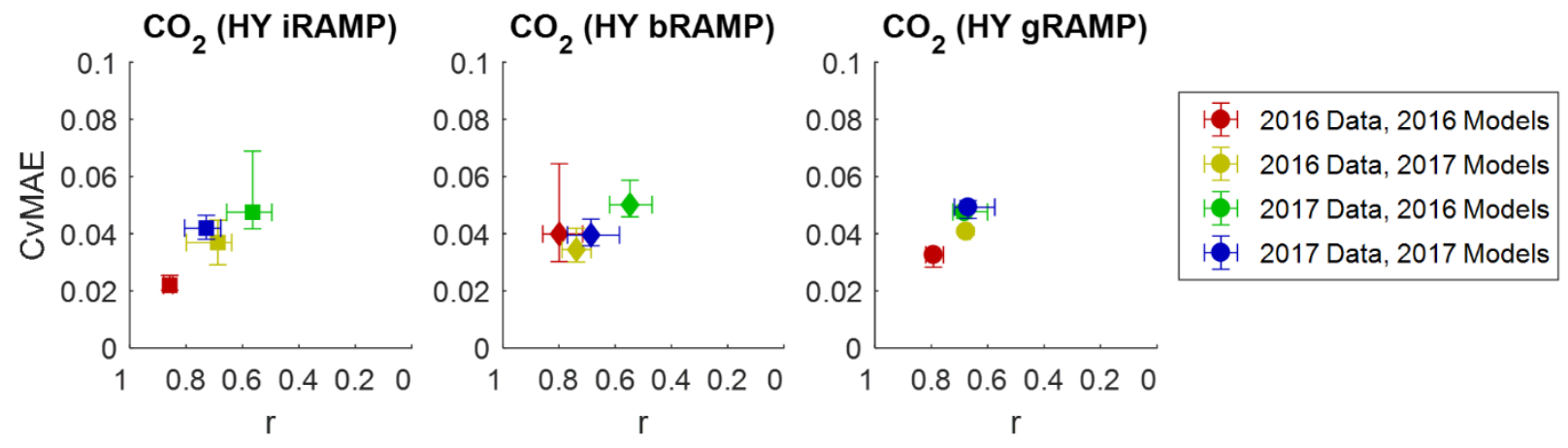

Figure S3. Results corresponding to Fig. 6 for $\mathrm{CO}_{2}$. 

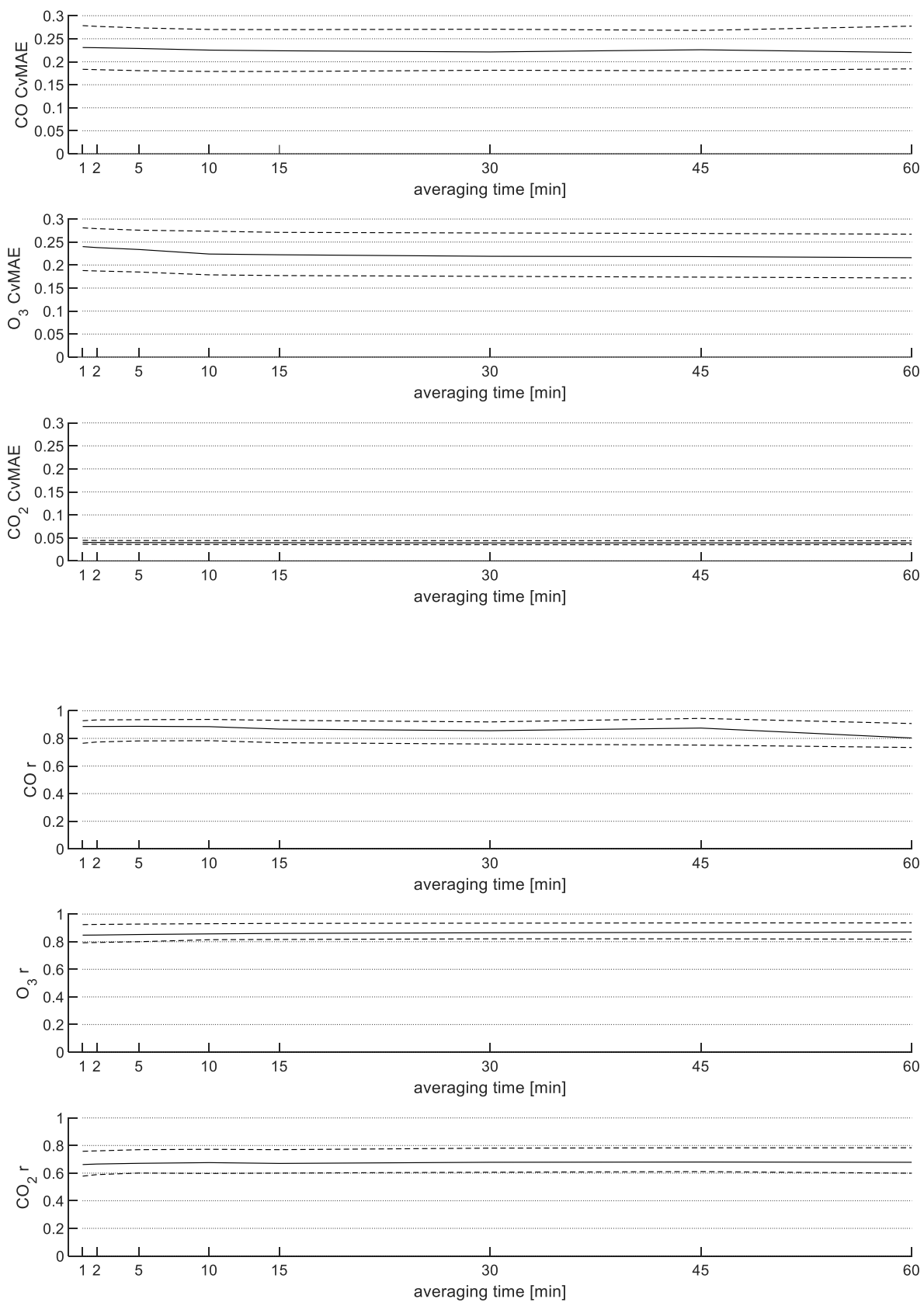

Figure S4. An evaluation of the performance of the calibration algorithms as a function of the averaging period applied to the raw RAMP data. All models are trained using data collected at the CMU site in 2017. Performance is also evaluated at the CMU site in 5 2017. Solid lines indicate median performance across RAMPs, dashed lines indicate $25^{\text {th }}$ and $75^{\text {th }}$ percentiles of performance. For CO, the gRAMP LQR model is used; for $\mathrm{O}_{3}$ the gRAMP HY model is used; for $\mathrm{CO}_{2}$ the gRAMP HY model is used. Note that all models were originally developed using data averaged at 15 minutes. Results are presented for CvMAE and Pearson $\mathbf{r}$, for averaging times ranging from 1 minute up to 1 hour. These results indicate that the performance of the calibration approaches are fairly stable 
for data averaged over periods ranging up to 1 hour. At longer averaging periods, the use of time-averaged environmental variables (such as temperature and relative humidity) in the calibration model appears to reduce performance.
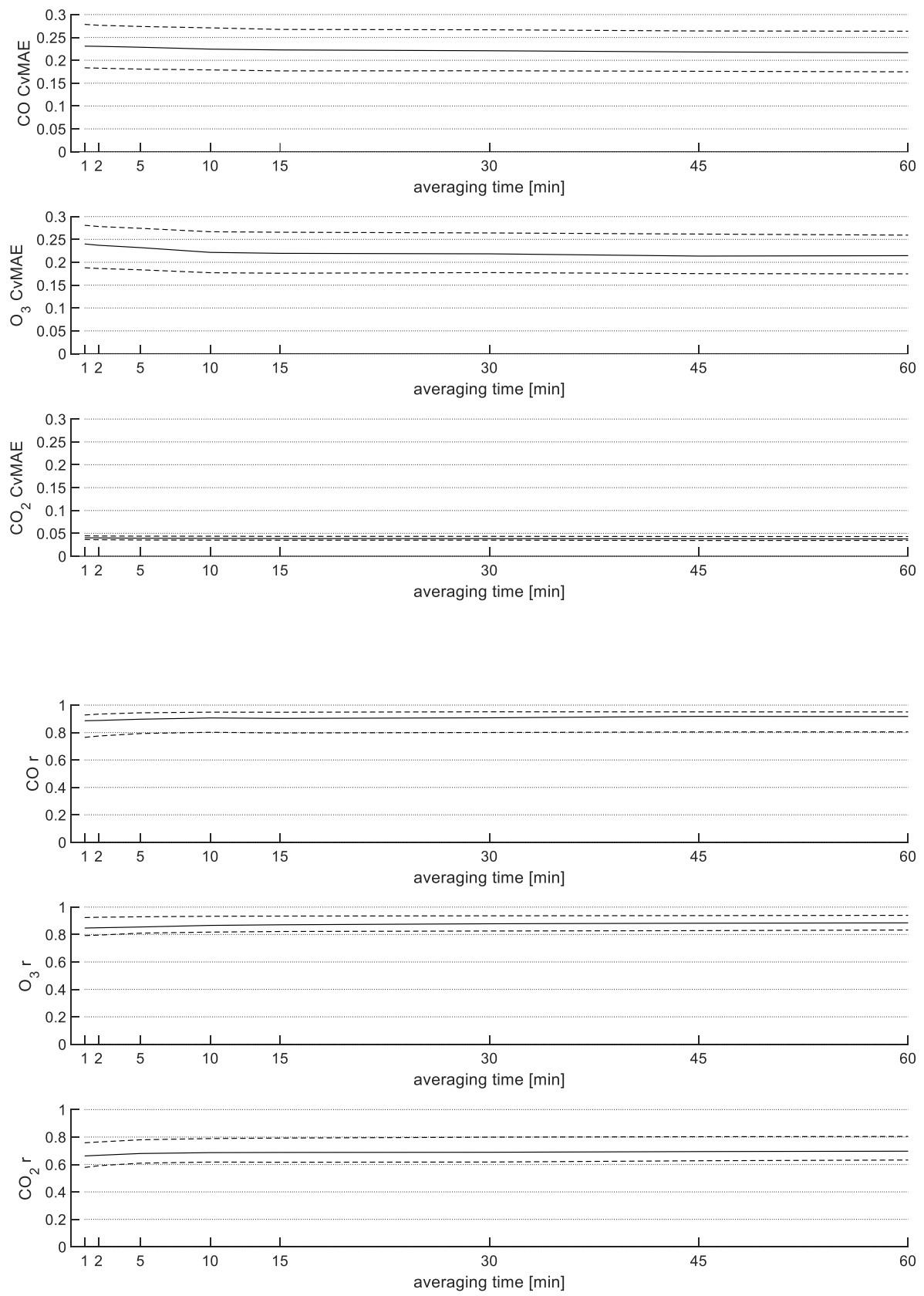

5 Figure S5. An evaluation of the performance of the calibration algorithms as a function of the averaging period; in contrast to the previous figure, this presents the results when averaging is performed after calibration, rather than before. In terms of CvMAE, performance improves as averaging time increases. In terms of Pearson r, results can be worse with longer averaging, due to the 
reduction in the number of points used to evaluate correlation (since there are fewer time periods overall to compare) and to the reduction in the variability (although accuracy is improving as averaging time increases, the variability in the data are also being reduced, and so correlation is decreasing).

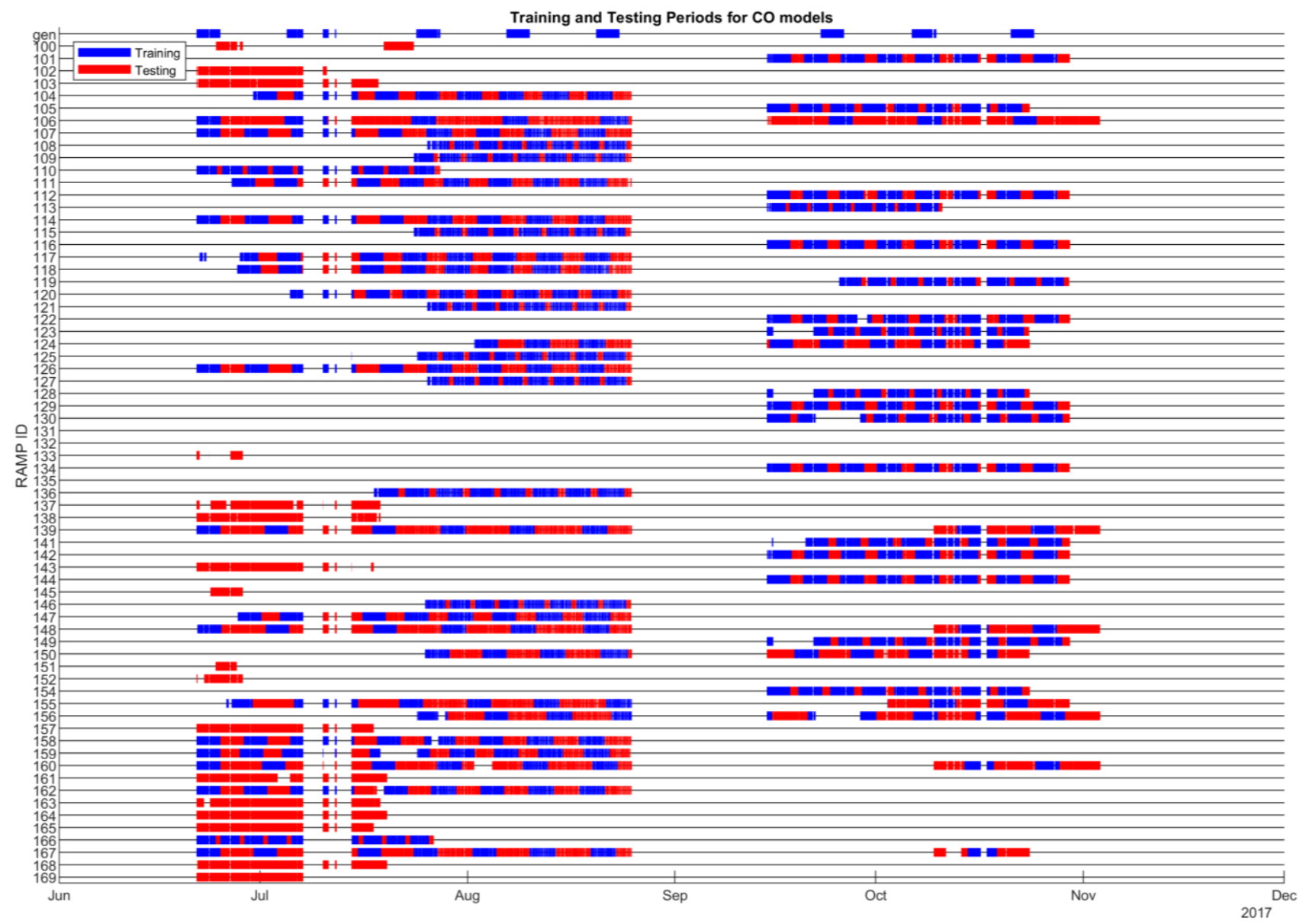

5 Figure S6. Description of the training and testing periods used for $\mathrm{CO}$ models. Blue bars indicate periods used for training data, while red bars denote periods set aside for testing. Time divisions for individual RAMPs (with numeric IDs) are presented corresponding to data used for iRAMP and bRAMP models. Divisions for the "gen" RAMP indicate the training data periods used for gRAMP models, derived from the median of data from the training set of RAMPs collected during these periods; testing data for gRAMP models is drawn from RAMPs which are not part of the training set of RAMPs. 


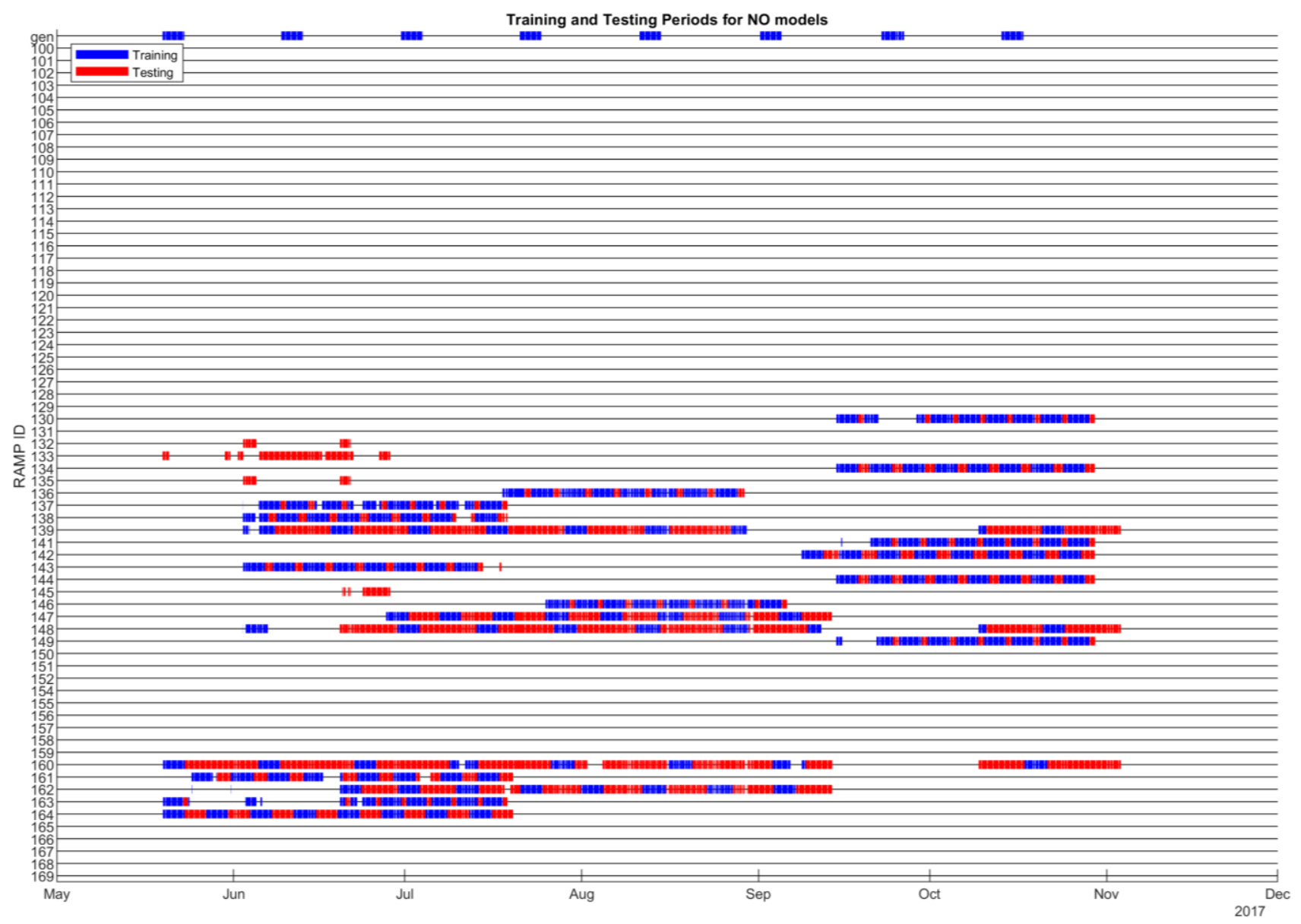

Figure S7. Description of the training and testing periods used for NO models. Blue bars indicate periods used for training data, while red bars denote periods set aside for testing. Time divisions for individual RAMPs (with numeric IDs) are presented corresponding to data used for iRAMP and bRAMP models. Divisions for the "gen" RAMP indicate the training data periods used

5 for gRAMP models, derived from the median of data from the training set of RAMPs collected during these periods; testing data for gRAMP models is drawn from RAMPs which are not part of the training set of RAMPs. 


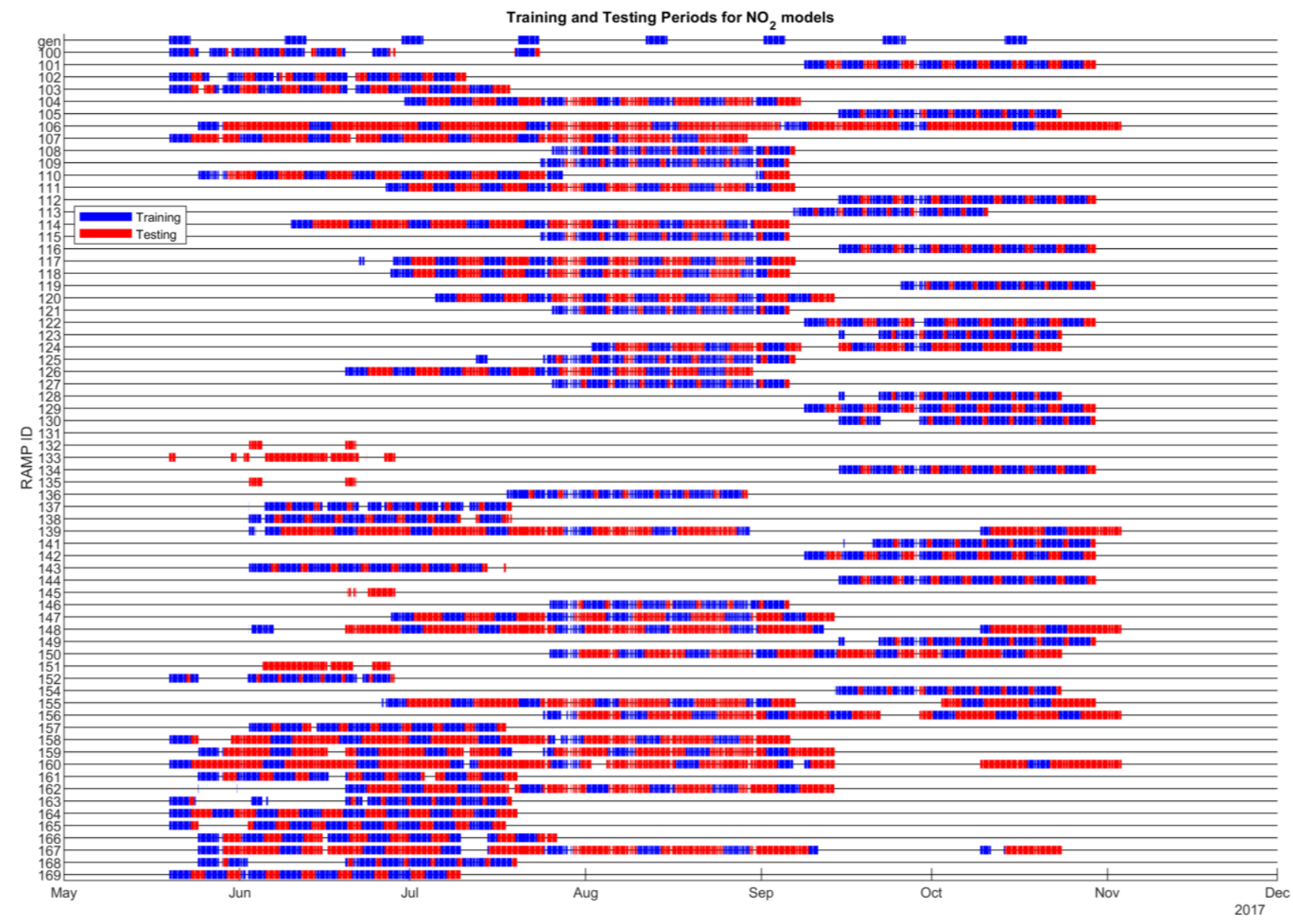

Figure S8. Description of the training and testing periods used for $\mathrm{NO}_{2}$ models. Blue bars indicate periods used for training data, while red bars denote periods set aside for testing. Time divisions for individual RAMPs (with numeric IDs) are presented corresponding to data used for iRAMP and bRAMP models. Divisions for the "gen" RAMP indicate the training data periods used

5 for gRAMP models, derived from the median of data from the training set of RAMPs collected during these periods; testing data for gRAMP models is drawn from RAMPs which are not part of the training set of RAMPs. 


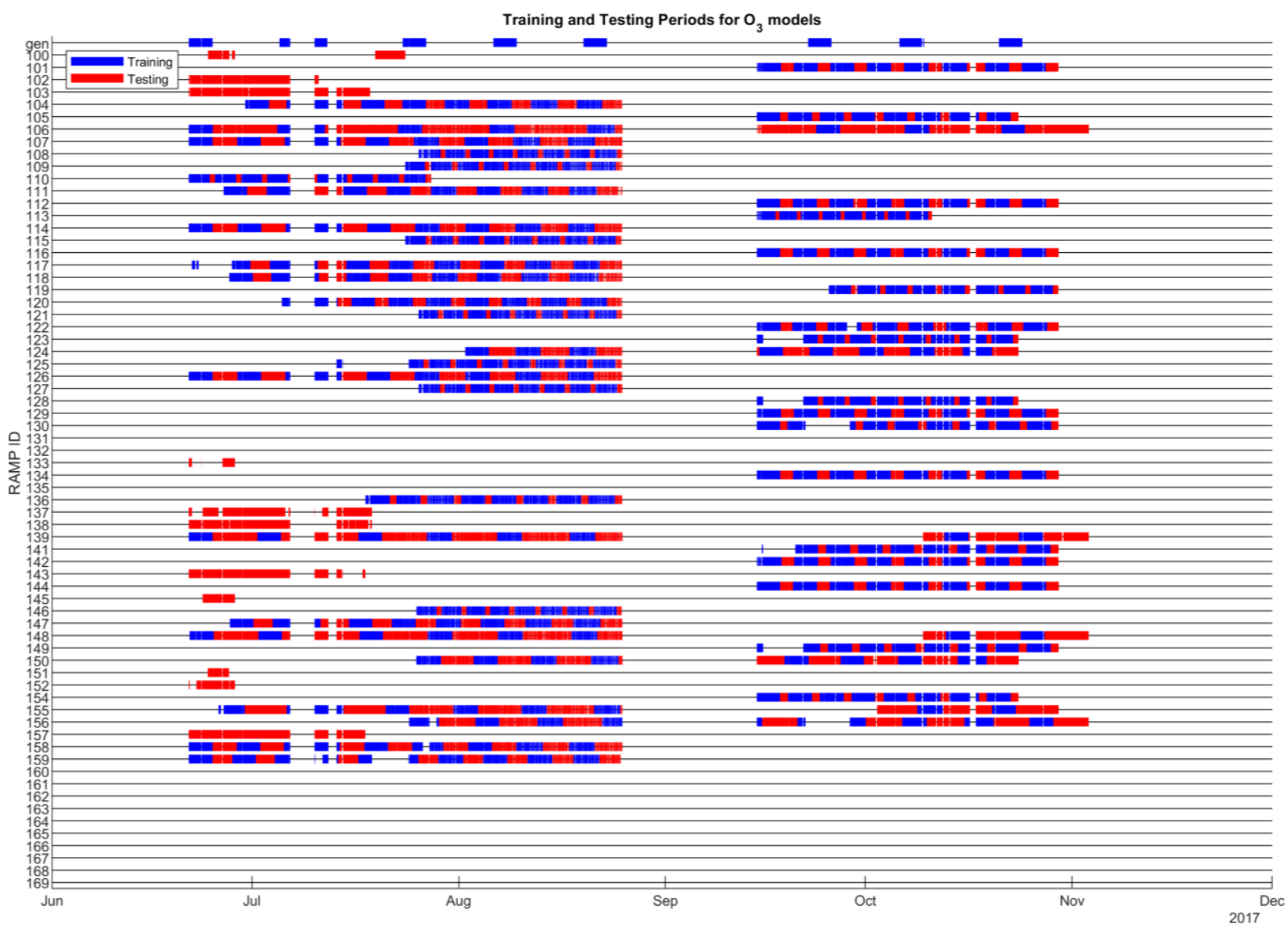

Figure S9. Description of the training and testing periods used for $\mathrm{O}_{3}$ models. Blue bars indicate periods used for training data, while red bars denote periods set aside for testing. Time divisions for individual RAMPs (with numeric IDs) are presented corresponding to data used for iRAMP and bRAMP models. Divisions for the "gen" RAMP indicate the training data periods used for gRAMP models, derived from the median of data from the training set of RAMPs collected during these periods; testing data for gRAMP models is drawn from RAMPs which are not part of the training set of RAMPs. 


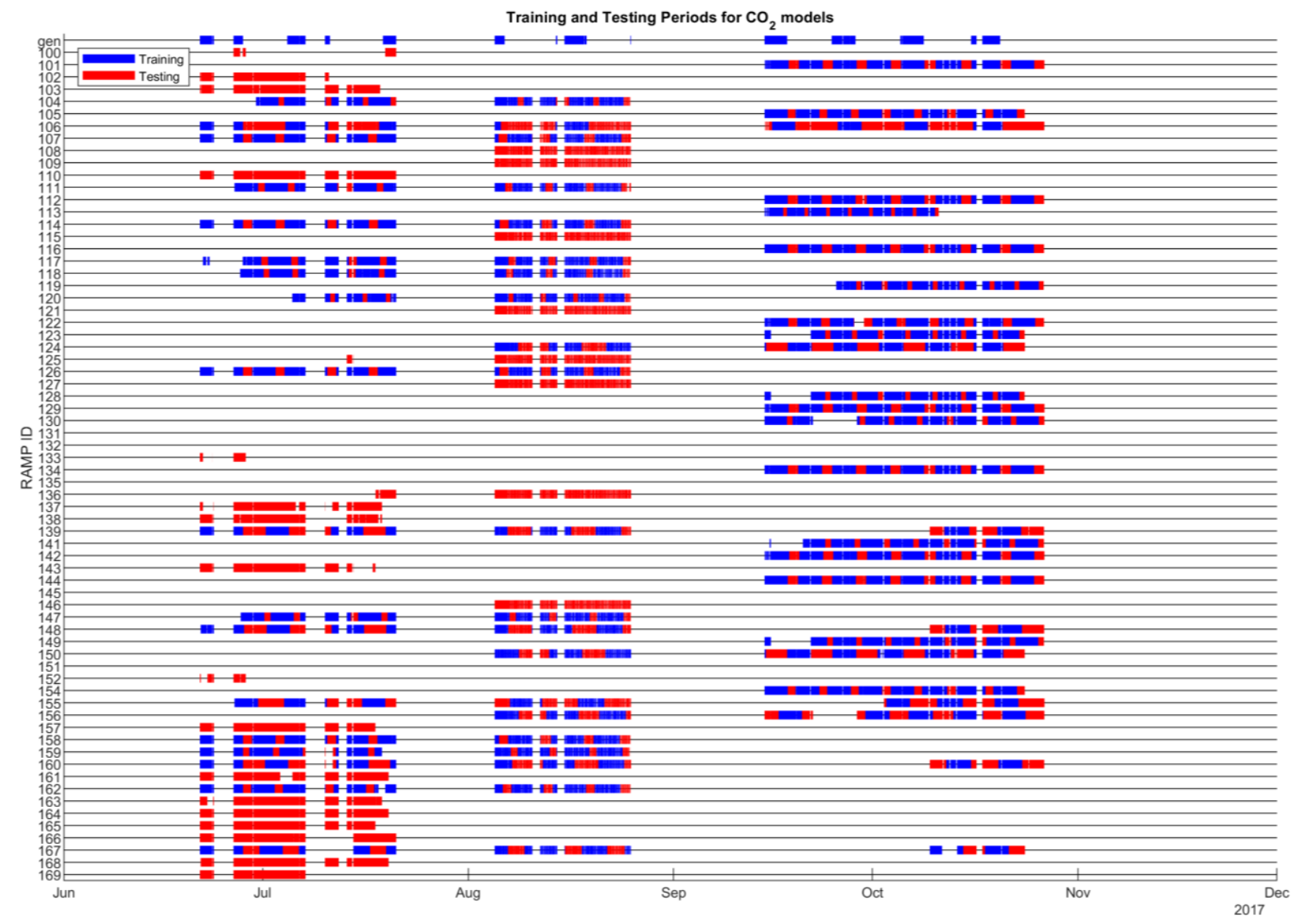

Figure S10. Description of the training and testing periods used for $\mathrm{CO}_{2}$ models. Blue bars indicate periods used for training data, while red bars denote periods set aside for testing. Time divisions for individual RAMPs (with numeric IDs) are presented corresponding to data used for iRAMP and bRAMP models. Divisions for the "gen" RAMP indicate the training data periods used

5 for gRAMP models, derived from the median of data from the training set of RAMPs collected during these periods; testing data for gRAMP models is drawn from RAMPs which are not part of the training set of RAMPs. 


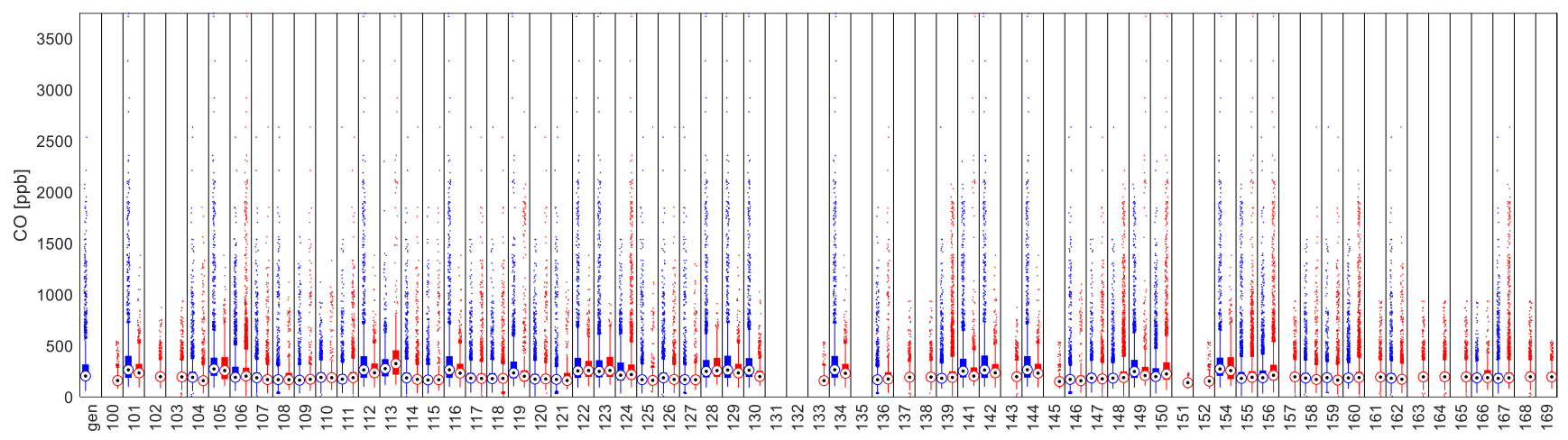

Figure S11. Depiction of the range of CO concentrations experienced during training and testing. Blue boxplots indicate training ranges, while red boxplots denote testing ranges. Dots with circles indicate the midpoint, thicker bars indicate the interquartile range, thinner bars show $1^{\text {st }}$ and $99^{\text {th }}$ percentiles, and colored dots depict outliers. The horizontal axis shows the RAMP ID number (or "gen", which depicts the concentration range used for training gRAMP models).

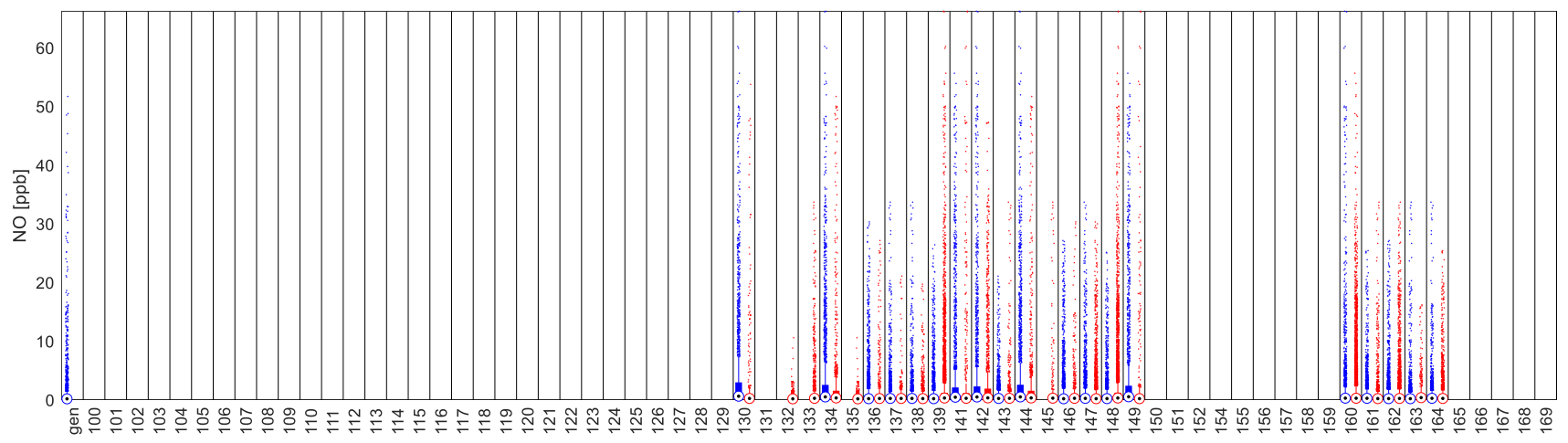

Figure S12. Depiction of the range of NO concentrations experienced during training and testing. Blue boxplots indicate training ranges, while red boxplots denote testing ranges. Dots with circles indicate the midpoint, thicker bars indicate the interquartile range, thinner bars show $1^{\text {st }}$ and $99^{\text {th }}$ percentiles, and colored dots depict outliers. The horizontal axis shows the RAMP ID number (or "gen", which depicts the concentration range used for training gRAMP models). 


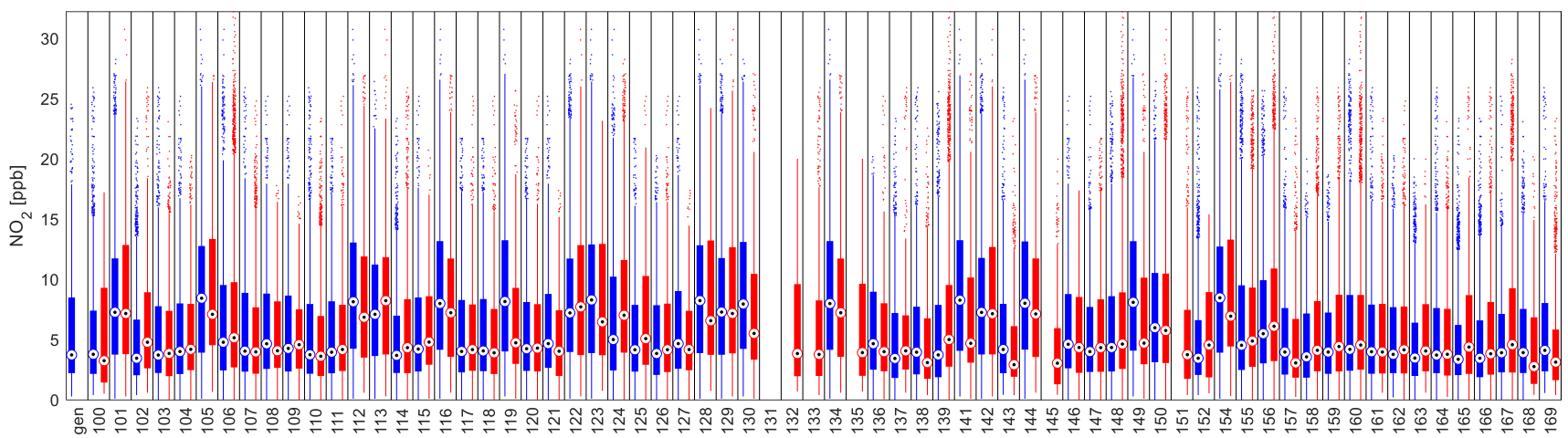

Figure S13. Depiction of the range of $\mathrm{NO}_{2}$ concentrations experienced during training and testing. Blue boxplots indicate training ranges, while red boxplots denote testing ranges. Dots with circles indicate the midpoint, thicker bars indicate the interquartile range, thinner bars show $1^{\text {st }}$ and $99^{\text {th }}$ percentiles, and colored dots depict outliers. The horizontal axis shows the RAMP ID number (or "gen", which depicts the concentration range used for training gRAMP models).

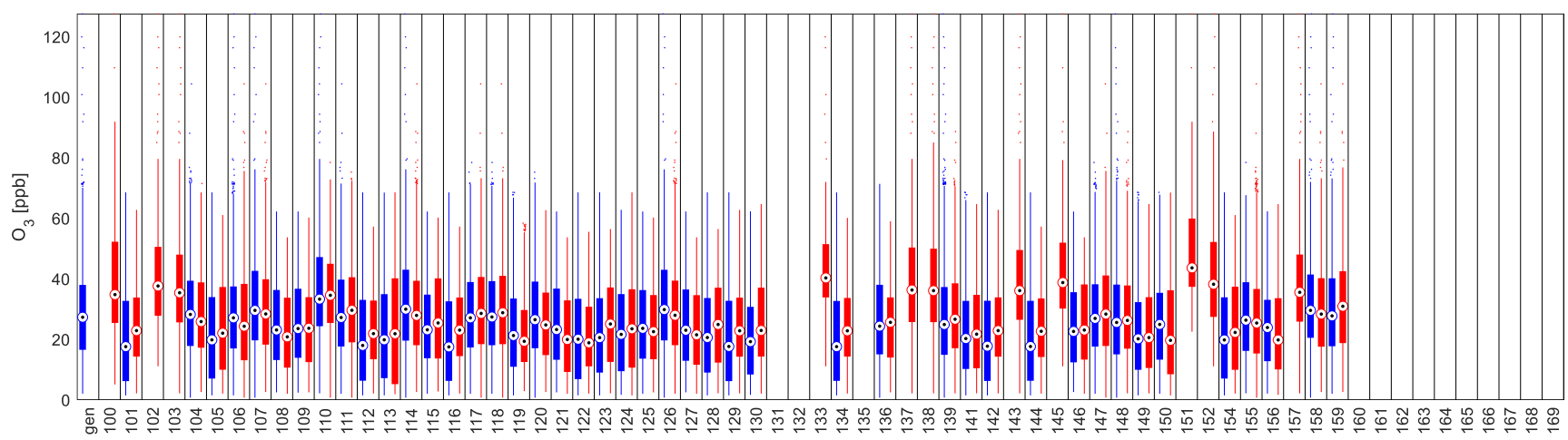

Figure S14. Depiction of the range of $\mathrm{O}_{3}$ concentrations experienced during training and testing. Blue boxplots indicate training ranges, while red boxplots denote testing ranges. Dots with circles indicate the midpoint, thicker bars indicate the interquartile range, thinner bars show $1^{\text {st }}$ and $99^{\text {th }}$ percentiles, and colored dots depict outliers. The horizontal axis shows the RAMP ID number (or "gen", which depicts the concentration range used for training gRAMP models). 


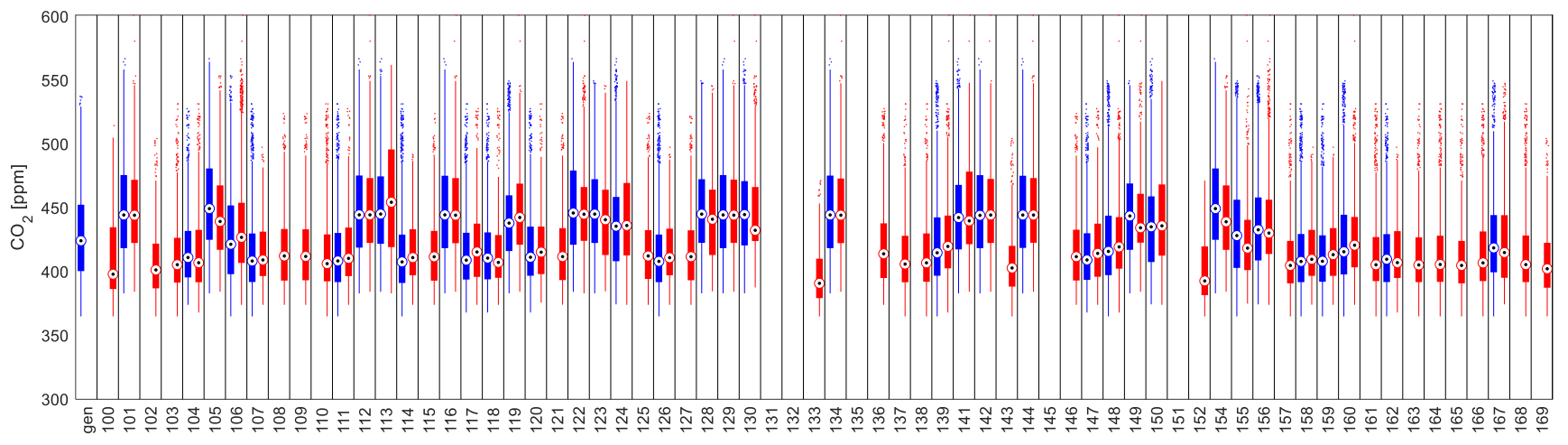

Figure S15. Depiction of the range of $\mathrm{CO}_{2}$ concentrations experienced during training and testing. Blue boxplots indicate training ranges, while red boxplots denote testing ranges. Dots with circles indicate the midpoint, thicker bars indicate the interquartile range, thinner bars show $1^{\text {st }}$ and $99^{\text {th }}$ percentiles, and colored dots depict outliers. The horizontal axis shows the RAMP ID number (or "gen", which depicts the concentration range used for training gRAMP models). 
Table S1: Results corresponding to Table 4 for $\mathrm{CO}_{2}$.

\begin{tabular}{|c|c|c|c|c|c|c|c|c|}
\hline \multirow[t]{4}{*}{ Gas } & \multicolumn{4}{|c|}{ Training Period } & \multicolumn{4}{|c|}{ Testing Period } \\
\hline & \multirow{3}{*}{$\begin{array}{c}\text { Duration } \\
\text { [days] } \\
\text { Range }\end{array}$} & \multicolumn{3}{|c|}{$\begin{array}{c}\text { Concentration } \\
{[\mathrm{ppm}]}\end{array}$} & \multirow{3}{*}{$\begin{array}{c}\text { Duration } \\
\text { [days] } \\
\text { Range }\end{array}$} & \multicolumn{3}{|c|}{$\begin{array}{c}\text { Concentration } \\
{[\mathrm{ppm}]}\end{array}$} \\
\hline & & lower & average & upper & & lower & average & upper \\
\hline & & range & range & range & & range & range & range \\
\hline $\mathrm{CO}_{2}$ & $21-28$ & $365-384$ & $413-454$ & $528-567$ & $2-50$ & $365-388$ & $399-458$ & $471-601$ \\
\hline
\end{tabular}

Table S2: Results corresponding to Table 5 for $\mathrm{CO}_{2}$.

\begin{tabular}{|c|c|c|c|c|c|c|c|c|c|c|}
\hline \multirow[t]{3}{*}{$\underline{\text { Gas }}$} & \multicolumn{2}{|c|}{ Model } & \multicolumn{8}{|c|}{ Testing Performance } \\
\hline & \multirow[t]{2}{*}{ Type } & \multirow[t]{2}{*}{ \# } & \multicolumn{2}{|c|}{ Slope } & \multicolumn{2}{|c|}{$\mathbf{r}^{2}$} & \multicolumn{2}{|c|}{$\begin{array}{c}\text { MAE } \\
{[\mathrm{ppm}]}\end{array}$} & \multicolumn{2}{|c|}{$\begin{array}{c}\text { Bias } \\
{[\mathrm{ppm}]}\end{array}$} \\
\hline & & & Avg. & $S D$ & Avg. & $S D$ & Avg. & $S D$ & Avg. & $S D$ \\
\hline \multirow[t]{6}{*}{$\mathrm{CO}_{2}$} & LR & 38 & 0.74 & 0.23 & 0.21 & 0.09 & 24 & 5 & 0.6 & 6.1 \\
\hline & LQR & 38 & 0.62 & 0.22 & 0.23 & 0.12 & 25 & 5 & 1.0 & 8.1 \\
\hline & CQR & 38 & 0.74 & 0.20 & 0.47 & 0.16 & 18 & 3 & -1.0 & 4.8 \\
\hline & CL & 38 & 0.76 & 0.13 & 0.43 & 0.13 & 20 & 3 & 1.4 & 4.4 \\
\hline & $\mathrm{NN}$ & 38 & 0.47 & 1.53 & 0.28 & 0.25 & 23 & 7 & -2.1 & 6.5 \\
\hline & $\mathrm{HY}$ & 38 & 0.79 & 0.26 & 0.53 & 0.15 & 19 & 4 & 3.2 & 6.0 \\
\hline
\end{tabular}


Table S3: Results corresponding to Table 5 for bRAMP models.

\begin{tabular}{|c|c|c|c|c|c|c|c|c|c|c|}
\hline \multirow[t]{3}{*}{$\underline{\text { Gas }}$} & \multicolumn{2}{|c|}{ Model } & \multicolumn{8}{|c|}{ Testing Performance } \\
\hline & \multirow[t]{2}{*}{ Type } & \multirow[t]{2}{*}{$\#$} & \multicolumn{2}{|c|}{ Slope } & \multicolumn{2}{|c|}{$\mathbf{r}^{2}$} & \multicolumn{2}{|c|}{$\begin{array}{l}\text { MAE } \\
{[\mathrm{ppb}]}\end{array}$} & \multicolumn{2}{|c|}{$\begin{array}{c}\text { Bias } \\
{[\mathrm{ppb}]}\end{array}$} \\
\hline & & & Avg. & $S D$ & Avg. & $S D$ & Avg. & $S D$ & Avg. & $S D$ \\
\hline \multirow[t]{6}{*}{$\mathrm{CO}$} & LR & 1 & 0.68 & 0.28 & 0.66 & 0.23 & 80 & 38 & 54 & 138 \\
\hline & LQR & 1 & 0.75 & 0.25 & 0.71 & 0.21 & 59 & 28 & 56 & 119 \\
\hline & CQR & 4 & 0.62 & 0.29 & 0.58 & 0.29 & 143 & 337 & 156 & 568 \\
\hline & $\mathrm{CL}$ & 4 & 0.83 & 0.31 & 0.64 & 0.23 & 66 & 29 & 63 & 78 \\
\hline & NN & 4 & 1.09 & 0.58 & 0.46 & 0.20 & 81 & 31 & 42 & 90 \\
\hline & HY & 4 & 0.74 & 0.26 & 0.69 & 0.24 & 63 & 38 & 98 & 90 \\
\hline \multirow[t]{6}{*}{$\mathrm{NO}$} & LR & 1 & 0.60 & 0.67 & 0.09 & 0.09 & 8.3 & 20.6 & 8.9 & 19.6 \\
\hline & LQR & 1 & 0.69 & 0.53 & 0.14 & 0.14 & 3.8 & 7.2 & 1.9 & 6.5 \\
\hline & CQR & 2 & 0.55 & 0.44 & 0.19 & 0.17 & 8.0 & 23.2 & 5.4 & 19.2 \\
\hline & $\mathrm{CL}$ & 2 & 0.38 & 0.35 & 0.09 & 0.13 & 3.1 & 1.7 & 1.1 & 1.4 \\
\hline & NN & 2 & 1.00 & 0.57 & 0.21 & 0.16 & 2.2 & 1.1 & 0.2 & 2.0 \\
\hline & HY & 2 & 0.58 & 0.31 & 0.26 & 0.15 & 2.5 & 1.8 & 1.4 & 2.2 \\
\hline \multirow[t]{6}{*}{$\mathrm{NO}_{2}$} & LR & 1 & 0.75 & 0.42 & 0.14 & 0.10 & 4.7 & 9.6 & -0.2 & 7.0 \\
\hline & LQR & 1 & 0.64 & 0.27 & 0.18 & 0.12 & 3.5 & 0.9 & -1.4 & 1.8 \\
\hline & CQR & 4 & 0.44 & 0.35 & 0.25 & 0.19 & 4.2 & 2.1 & 2.1 & 4.4 \\
\hline & $\mathrm{CL}$ & 4 & 0.58 & 0.29 & 0.21 & 0.14 & 3.5 & 0.6 & 2.1 & 2.9 \\
\hline & $\mathrm{NN}$ & 4 & 0.86 & 0.37 & 0.33 & 0.18 & 3.1 & 0.7 & 0.5 & 2.4 \\
\hline & HY & 4 & 0.78 & 0.30 & 0.32 & 0.19 & 3.2 & 1.2 & 1.4 & 2.5 \\
\hline \multirow[t]{6}{*}{$\mathrm{O}_{3}$} & LR & 1 & 0.76 & 0.24 & 0.70 & 0.23 & 10.5 & 24.8 & 4.7 & 21.5 \\
\hline & LQR & 1 & 0.85 & 0.22 & 0.72 & 0.24 & 6.1 & 3.1 & -3.1 & 8.9 \\
\hline & CQR & 2 & 0.75 & 0.27 & 0.65 & 0.27 & 9.8 & 17.1 & 2.9 & 15.5 \\
\hline & $\mathrm{CL}$ & 2 & 0.91 & 0.30 & 0.50 & 0.18 & 8.7 & 2.1 & -1.7 & 8.2 \\
\hline & NN & 2 & 0.90 & 0.53 & 0.65 & 0.26 & 7.0 & 3.9 & -2.6 & 7.4 \\
\hline & $\mathrm{HY}$ & 2 & 1.06 & 0.21 & 0.75 & 0.13 & 5.8 & 1.8 & 0.3 & 6.5 \\
\hline \multirow[t]{6}{*}{$\mathrm{CO}_{2}$} & LR & 1 & 0.65 & 0.40 & 0.18 & 0.14 & 23 & 5 & 13 & 19 \\
\hline & LQR & 1 & 0.41 & 0.32 & 0.16 & 0.16 & 27 & 9 & 15 & 25 \\
\hline & CQR & 4 & 0.43 & 0.27 & 0.31 & 0.21 & 58 & 171 & 17 & 148 \\
\hline & $\mathrm{CL}$ & 4 & 0.70 & 0.18 & 0.32 & 0.15 & 21 & 4 & 9 & 17 \\
\hline & NN & 4 & 0.79 & 0.53 & 0.29 & 0.18 & 31 & 32 & -9 & 46 \\
\hline & $\mathrm{HY}$ & 4 & 0.95 & 0.27 & 0.47 & 0.16 & 18 & 3 & 12 & 17 \\
\hline
\end{tabular}


Table S4: Results corresponding to Table 5 for gRAMP models.

\begin{tabular}{|c|c|c|c|c|c|c|c|c|c|c|}
\hline \multirow[t]{3}{*}{$\underline{\text { Gas }}$} & \multicolumn{2}{|c|}{ Model } & \multicolumn{8}{|c|}{ Testing Performance } \\
\hline & \multirow[t]{2}{*}{ Type } & \multirow[t]{2}{*}{$\#$} & \multicolumn{2}{|c|}{ Slope } & \multicolumn{2}{|c|}{$\mathbf{r}^{2}$} & \multicolumn{2}{|c|}{$\begin{array}{l}\text { MAE } \\
{[\mathrm{ppb}]}\end{array}$} & \multicolumn{2}{|c|}{$\begin{array}{c}\text { Bias } \\
{[\mathrm{ppb}]}\end{array}$} \\
\hline & & & Avg. & $S D$ & Avg. & $S D$ & Avg. & $S D$ & Avg. & $S D$ \\
\hline \multirow[t]{6}{*}{$\mathrm{CO}$} & LR & 1 & 1.03 & 0.24 & 0.80 & 0.11 & 68 & 12 & 26 & 109 \\
\hline & LQR & 1 & 0.90 & 0.08 & 0.85 & 0.09 & 56 & 8 & 6 & 93 \\
\hline & CQR & 1 & 0.69 & 0.18 & 0.66 & 0.20 & 106 & 41 & 60 & 95 \\
\hline & $\mathrm{CL}$ & 1 & 1.02 & 0.19 & 0.72 & 0.10 & 80 & 12 & 21 & 57 \\
\hline & NN & 1 & 0.67 & 0.22 & 0.51 & 0.17 & 134 & 59 & 88 & 111 \\
\hline & HY & 1 & 0.75 & 0.11 & 0.61 & 0.11 & 110 & 41 & 75 & 54 \\
\hline \multirow[t]{6}{*}{$\mathrm{NO}$} & LR & 1 & 1.51 & 0.92 & 0.07 & 0.03 & 3.8 & 1.8 & 0.1 & 1.8 \\
\hline & LQR & 1 & 0.67 & 0.34 & 0.08 & 0.04 & 7.1 & 9.6 & 3.5 & 8.5 \\
\hline & CQR & 1 & 0.15 & 0.09 & 0.06 & 0.04 & 5.9 & 6.4 & 2.7 & 6.3 \\
\hline & $\mathrm{CL}$ & 1 & 0.43 & 0.13 & 0.13 & 0.03 & 3.1 & 1.0 & -0.6 & 0.5 \\
\hline & NN & 1 & 0.49 & 0.23 & 0.22 & 0.12 & 4.1 & 3.0 & 2.3 & 4.9 \\
\hline & HY & 1 & 0.40 & 0.22 & 0.17 & 0.08 & 13.2 & 22.7 & 9.9 & 20.1 \\
\hline \multirow[t]{6}{*}{$\mathrm{NO}_{2}$} & LR & 1 & 1.07 & 0.40 & 0.14 & 0.05 & 3.9 & 0.7 & -1.2 & 1.5 \\
\hline & LQR & 1 & 0.86 & 0.31 & 0.18 & 0.07 & 3.8 & 0.7 & -1.1 & 1.9 \\
\hline & CQR & 1 & 0.67 & 0.21 & 0.30 & 0.09 & 3.5 & 0.4 & -1.0 & 2.7 \\
\hline & $\mathrm{CL}$ & 1 & 0.67 & 0.19 & 0.26 & 0.12 & 3.6 & 0.5 & -0.1 & 2.4 \\
\hline & $\mathrm{NN}$ & 1 & 0.88 & 0.21 & 0.34 & 0.15 & 3.3 & 0.4 & -0.3 & 2.9 \\
\hline & HY & 1 & 0.76 & 0.27 & 0.30 & 0.17 & 3.4 & 0.5 & 0.2 & 2.6 \\
\hline \multirow[t]{6}{*}{$\mathrm{O}_{3}$} & LR & 1 & 0.89 & 0.27 & 0.72 & 0.22 & 6.4 & 2.8 & 2.2 & 4.9 \\
\hline & LQR & 1 & 0.77 & 0.29 & 0.66 & 0.24 & 7.5 & 4.1 & 4.4 & 6.8 \\
\hline & CQR & 1 & 0.76 & 0.28 & 0.67 & 0.25 & 7.2 & 4.2 & 3.5 & 6.5 \\
\hline & $\mathrm{CL}$ & 1 & 0.91 & 0.13 & 0.45 & 0.19 & 8.9 & 1.8 & -0.8 & 5.7 \\
\hline & NN & 1 & 0.92 & 0.18 & 0.73 & 0.18 & 5.9 & 2.4 & 1.7 & 5.1 \\
\hline & $\mathrm{HY}$ & 1 & 1.00 & 0.12 & 0.73 & 0.12 & 5.9 & 1.5 & 0.9 & 2.9 \\
\hline \multirow[t]{6}{*}{$\mathrm{CO}_{2}$} & LR & 1 & 0.63 & 0.14 & 0.21 & 0.06 & 26 & 4 & -2 & 12 \\
\hline & LQR & 1 & 0.55 & 0.14 & 0.20 & 0.06 & 27 & 4 & -6 & 12 \\
\hline & CQR & 1 & 0.39 & 0.11 & 0.22 & 0.11 & 27 & 5 & -9 & 15 \\
\hline & $\mathrm{CL}$ & 1 & 0.71 & 0.15 & 0.37 & 0.13 & 23 & 2 & 3 & 16 \\
\hline & NN & 1 & 0.30 & 0.25 & 0.15 & 0.12 & 38 & 25 & -12 & 19 \\
\hline & $\mathrm{HY}$ & 1 & 0.80 & 0.16 & 0.43 & 0.11 & 21 & 2 & 4 & 15 \\
\hline
\end{tabular}

